\title{
Collateral effects of a pension reform in France.
}

\author{
Hélène Blake*and Clémentine Garrouste
}

December 4, 2017

\begin{abstract}
We measure the effects of the 1993 French pension reform on health, especially the reform has gradually increased the length of the contribution period required to benefit from a full pension, as well as the number of earnings years taken into account to calculate pension benefits. Most importantly, the reform heterogeneously has affected different cohorts of individuals, creating a quasi-experimental framework. Given that this reform concerned only private sector workers, we use the results of a survey on health ran in 2005 and a difference-in-differences analysis to compare health outcomes between two population samples, one composed of private sector workers and another of public sector workers. The results show significant differences between these two samples in two health measures - perceived health and physical health - but concentrated on less-educated individuals exclusively.
\end{abstract}

JEL codes : C010, I14, J14, J26

Keywords : Health, Pension Reform, Difference-in-Differences analysis

\footnotetext{
${ }^{*}$ Paris School of Economics (PSE), 48 Boulevard Jourdan Paris 75014.

${ }^{\dagger}$ Université Paris-Dauphine, PSL Research University, LEDa-LEGOS, 75016 Paris, France.

${ }^{\ddagger}$ We are very grateful to Arnaud Gautier and François Beck for providing data. We also thank seminar participants at PSE and at Sciences Po, Workshop on Health and Econometrics, EEA. We are particularly grateful to Yann Algan, Thomas Barnay, Didier Blanchet, Eric Bonsang, Antoine Bozio, Thomas Breda, Charlotte Cabane, Eve Caroli, Andrew Clark, Laurent Davezies, Brigitte Dormont, Lucie Gadenne, Thibault Gajdos, Pierre-Yves Geoffard, Mathilde Godard, Jérôme Le, Marion Leturcq, Maarten Lindeboom, Eric Maurin, Owen O'Donnell, Muriel Roger, Anne-Laure Samson and Nicolas Sirven who took some of their time to read the present article and make fruitful suggestions. We gratefully acknowledge financial supports from the Health Chair - a joint initiative by PSL, Université Paris Dauphine, ENSAE, MGEN and ISTYA under the aegis of the Fondation du Risque (FDR).
} 


\section{Introduction}

The relationship between work and health is a political concern, especially if this link is heterogeneous among the population. It could generate or increase inter and intragenerational health inequalities. Moreover, social security budget may be impacted by workers' health in two possible ways. On the one hand, bad health decreases life expectancy (all things being equal) and thus the number of people who receive a pension, which, in turn, increases the benefits of Social Security. On the other hand, since one constituent of Social Security is the coverage of health spending, social security budget could be deteriorated by workers' health decline.

Facing strong budgetary constraints, governments implemented retirement reforms aiming at reducing costs, by increasing working time. In France, recent studies analyzed the potential role of social security programs incentives on retirement in France (Behaghel et al., 2016; Bozio, 2008, 2011). Numerous studies are interested in the effect of major pension reforms on retirement, among them the 1993 reform, using econometrics tools and micro-simulation techniques (Mahieu and Blanchet, 2004; Salem et al., 2012; Walraet and Mahieu, 2012). New stakes have emerged since incentives to work longer may affect older individuals health. However, the relation between work and health is far from obvious. In fact, delaying retirement can entail stress and strain detrimental to health, as confirmed by Ekerdt et al. (1983). Symmetrically, Bound and Waidmann (2008) find evidence that retirement has a positive, albeit temporary, effect on masculine (but not feminine) health in the United Kingdom. Coe and Lindeboom (2008) show that retirement has a positive effect on subjective measurements of health in the United States. Coe and Zamarro (2011) find a similar effect in Europe using SHARE (Survey of Health, Ageing and Retirement in Europe). Eibich (2015) shows a long-run improvement in health upon retirement in Germany. Caroli et al. (2016) show that health care utilization increases when individuals retire. Brockmann et al. (2009) show that earlier retirement reduces mortality depending on the health status in Germany. Bloemen et al. (2017), using a temporary decrease in the age of eligibility benefits in the Netherlands, find that early retirement decreases the mortality for men.

Conversely, a number of studies show that retirement has a negative effect on cognitive functioning in the United States and in Europe (Bingley and Martinello, 2013; Bonsang et al., 2012; Mazzonna and Peracchi, 2012; Rohwedder and Willis, 2010) ${ }^{1}$ and increases

\footnotetext{
${ }^{1}$ Earlier studies argue that retirement may be stressful and associated with the mental impacts of feeling older and loneliness (Bradford, 1979; Carp, 1967; Eisdorfer and Wilkie, 1977; Macbride, 1976; Sheppard, 1976).
} 
probability of being obese (Godard, 2016). Bamia et al. (2007) show that early retirement is associated with higher mortality in Greece. Kuhn et al. (2010) find a positive effect of early retirement on the probability of dying before age 67 in Austria. Mazzonna and Peracchi (2017) find evidence of heterogeneous effects of retirement across occupational groups. They find that retirement increases the age-related decline of health and cognitive abilities for most workers, but they also find evidence of an immediate positive effect of retirement for those employed in highly physically demanding jobs. Nevertheless, some studies find no effect of retirement age on mortality: Hernaes et al. (2013) use a series of policy changes in Norway that reduced the retirement age for a part of the population. Hagen (2018) finds no evidence of an increase in retirement age on mortality and health care utilization for Swedish women. Thus, to our knowledge, there is no consensus in the literature as to a predominant effect of an increase of working time on health, or on the causal impact of retirement on health. ${ }^{2}$

The main issue to measure the effects of work on health is that reverse causality may conceal the effect of work on health (less healthy people may be inclined to leave employment more easily, whereas healthier people tend to stay on the labor market i.e. "healthy worker effect", which would create a positive correlation between work and health). ${ }^{3}$ This creates a selection bias. Lindeboom and Kerkhofs (2004) find that health has a strong effect on work choices and that health slowly deteriorates when work becomes more strenuous using rich panel data on Dutch seniors' employment and health (with subjective and objective variables).

To address this endogeneity issue, we use a French pension reform, which created heterogeneity in work incentives among seniors, to investigate whether an increase in working life affects the several dimensions of health. The French pension system is a payas-you-go system and its equilibrium depends on the employee-retiree ratio. This balance is in jeopardy as baby boomers leave the labor market and life expectancy lengthens. French governments have been implementing a set of reforms for more than 20 years. In 1993, the French government gradually increased incentives for seniors to work in

\footnotetext{
${ }^{2}$ One of the reason for this lack of consensus is the variety of definitions for health which do not coincide perfectly. An indicator of health at the country level is life expectancy and being in good health is defined as having a weak propensity to die. It is the most objective indicator but not totally sufficient since it allows no precise variation and does not presume good health (as an illustration, firemen who have a high propensity to die compared to the rest of the population still cannot be considered as in bad health). The notion of "healthy life years" developed by the European Union shows that good health cannot be resumed as a long life. It is defined by the number of disability-free years, which gives a negative and functional definition of health. Another dimension of health is given by the World Health Organization (WHO) which argues for a definition of health as "a state of complete physical, mental and social well-being, and not merely the absence of disease or infirmity".

${ }^{3}$ See Blanchet and Debrand (2008), Kalwij and Vermeulen (2008), and Pagan (2011) on part-time work in the case of disability.
} 
the private sector. ${ }^{4}$ Our identification strategy is based on the 1993 reform which was exogeneously introduced. For each generation, the government increased incentives via two main tools: the contribution period required to entitle a full pension and the number of reference earning years taken to calculate pensions. This reform is a good example of natural experiment since it was implemented independently of individuals characteristics, the increase in working incentives depended only of their birth year. ${ }^{5}$ We study the impact of the 1993 reform on workers' health using a difference-in-differences analysis. Our method consists in comparing individuals with different incentives to work. We take public sector employees as a control group since the reform did not concern them. We find a negative effect of the 1993 reform on perceived and physical health, which is driven by less educated seniors.

We contribute to the literature in several ways. First, we develop an identification strategy which is different from those previously employed in the literature. We consider the effect of a French pension reform on health, whereas previous studies use eligibility ages for pension benefits as instrumental variables for retirement across states or country (Coe and Lindeboom, 2008; Coe and Zamarro, 2011; Mazzonna and Peracchi, 2012, 2017; Rohwedder and Willis, 2010). This ensures that our results cannot be biased by countryspecific or state-specific effect. Second, we measure the effect of a pension reform (which aims at delaying retirement), whereas most studies measure the impact of early retirement on health. These two effects are not necessary symmetric: for instance, an increase in working time could have no effect on health, whereas retirement could have a positive or a negative impact. In the same way, some studies measured the effect of reduction of working time on health-related behaviors (Berniell and Bietenbeck, 2017), however reduction of working time could have an asymmetrical effect on health compared to an increase in working time (elasticities may be different depending on the sign of the variation). As this reform made the index-linking of pensions to inflation official, all in all, pensions fell a total of $8 \%$ between 1994 and 2003 (Bridenne and Brossard, 2008). Consequently it may be difficult to determine the potential mechanisms which explain the negative effect of the 1993 reform on health.

The paper is structured as follows: Section 2 presents the institutional framework and

\footnotetext{
${ }^{4}$ Unexpectedly, the OECD statistics do not show an increase in average age of retirement in France after 1993 . On the contrary, they show a slight decrease up to 2005: http://www.oecd.org/els/emp/average-effective-age-of-retirement.htm. However, a study based on the EU labor Force Survey microdata and a difference-in-differences approach, Aliaj et al. (2016) estimate for France a significant increase of the 50-64 year-old employment rates, specifically after 2001.

${ }^{5}$ The main purpose of the government was to reduce the deficit of the Health System and did not expect the potential collateral effects of this reform on health. In France, the consequences of hardness of work was taken into account much later.
} 
the 1993 French pension reform. Section 3 presents the data and some descriptive statistics. Section 4 presents the empirical strategy and Section 5 the difference-in-differences results.

\section{Institutional framework}

\subsection{Pension schemes in the private sector before the reform}

There are various pension schemes in France. Private sector workers pay into a general mandatory pay-as-you-go pension scheme. Pension amounts depend on the time workers contribute to this system hence the length of working life in the private sector and their best-earning years. Before 1993, workers had to contribute for 37.5 years to be entitled to a full pension and the amount paid was proportional to the average wages of the best-earning years. This amount was calculated as follows:

$$
P=\tau \times \omega_{r} \times \min \left(1, \frac{d}{150}\right)
$$

where $P$ denotes the pension level, $d$ the number of contribution quarters, $w_{r}$ the reference wage and $\tau$ is computed as follows:

$$
\tau=0.5-\delta \times \max [0, \min (4 \times(65-a), 150-d)]
$$

where $\delta$ is the minimization coefficient, equal to $1.25 \%$ per quarter of missing contributions (5\% per year), and $a$ is the age on drawing the pension (i.e. retirement age). Pension amounts are dictated by contributions not made before age 65 or before reaching 150 contribution quarters. ${ }^{6}$ If a worker retires at 65 or contributes to the general system for more than 37.5 years, there is no pension reduction. In this case, the replacement rate (that is $\frac{P}{w_{r}}$ ) is $50 \%$. $^{7}$

\subsection{Pension schemes in the public sector}

Individuals who worked in the public sector are subject to the same legal retirement age as private sector workers, i.e. 60 years up to the 1951 generation (before the 2010 reform).

\footnotetext{
${ }^{6}$ For instance, if the pension drawing age is 61 and the number contribution quarters is 140 , then $4 \times(65-61)=16$ and $150-140=10$. The individual would have to contribute 10 more quarters to reach 150 contribution quarters and 16 more quarters before reaching 65 years old. The pension is computed taking the smallest difference (10) (see (Bozio, 2011)).

${ }^{7}$ The individual in the previous example has an underestimated pension which corresponds to $1.25 \%$ per quarter, i.e. $12.5 \%, \tau$ is then $0.5-0.0125 \times 10=0.375=37,5 \%$ for an individual aged 61 who contributes 140 quarters. This individual's replacement rate is then: $P / \omega_{r}=\tau \times \min \left(1, \frac{d}{150}\right)=0.375 \times 140 / 150=0.35$.
} 
Retirement in the civil service generally takes place at the normal age (legal age) and thereafter (up to 65). However, the average wages of the last 6 months is taken into account to calculate the pension amount (compared to 10 years in the private sector), the replacement rate is $75 \%$ of the last 6 months' wages before retirement, which is more than in the private sector ( $50 \%$ rate). The 1944 generation is the first one affected by the 2003 reform in the public sector, which is why we take into account generations 1928 to 1943 in our analysis. The government gradually increased the number of quarters required to get a full pension with the aim of converging the public and private sectors. Individuals born prior to or in 1943 have to contribute 150 quarters to obtain a full pension in the public sector. ${ }^{8}$

\subsection{The 1993 pension reform}

In 1993, the government led by Prime Minister E. Balladur chose to reform the general pension system. This reform did not concern public sector employees ${ }^{9}$. We describe the implementation of the 1993 reform in Table 1. First, the number of years of contributions required for a full pension was gradually raised from 37.5 to 40 years, cohort by cohort, starting with the 1934 generation. As shown by Table 1, the number of contribution quarters required for a full pension increased by one quarter per year: 150 for the 1933 generation (in 1993) and 151 for the 1934 generation (in 1994) and so on, through to 160 for the 1943 generation (in 2003). Second, the reform reduced the reference wage by gradually raising the number of years required for its calculation with each generation from 10 to 20 years for individuals born in 1943. Third, the reference wage was indexed on prices (but this last measure does not vary by cohort). Equation (2) then becomes:

$$
\tau^{\prime}=0.5-\delta \times \max [0, \min (4 \times(65-a), D-d)]
$$

where $D$, the needed quarters required for a full pension, goes from 150 to 160 according to the generation.

Figure 1 shows the effect of the reform as regards incentives to work comparing two seniors who had contributed 140 quarters at age 60: the first one is concerned by the

\footnotetext{
${ }^{8}$ More precisely, the 2003 reform extended the 1993 reform to include civil servants, implementing a convergence between the 150 contributed quarters for the 1943 generation to 160 for the 1948 generation (the number of contributed quarters has increased by two quarters per birth year). The 2003 reform has increased the number of contributed quarters to reach 163 quarters for the 1951 generation (for the two sectors). The 2003 reform introduced, on the one hand, an increase of the contribution period required to get a full pension and has led to an increase in the proportion of retirement after 60 years. On the other hand, the long career mechanism, from the same reform, has led to an increase in the proportion of early retirements before age 60 (Soulat et al., 2014). Thus, there are two contradicting effects on retirement age following the 2003 reform.

${ }^{9}$ See the act of 22 July 1993.
} 
Table 1: Heterogeneity in the treatment by generation

\begin{tabular}{ccccc} 
Generation & Age in 1993 & Age in 2005 & Nb of contributed quarters & Nb of reference years \\
\hline 1928 & 65 & 77 & 150 & 10 \\
1929 & 64 & 76 & 150 & 10 \\
1930 & 63 & 75 & 150 & 10 \\
1931 & 62 & 74 & 150 & 10 \\
1932 & 61 & 73 & 150 & 10 \\
1933 & 60 & 72 & 150 & 10 \\
\hline 1934 & 59 & 71 & 151 & 11 \\
1935 & 58 & 70 & 152 & 12 \\
1936 & 57 & 69 & 153 & 13 \\
1937 & 56 & 68 & 154 & 14 \\
1938 & 55 & 67 & 155 & 16 \\
1939 & 54 & 66 & 156 & 17 \\
1940 & 53 & 65 & 157 & 18 \\
1941 & 52 & 64 & 158 & 19 \\
1942 & 51 & 63 & 159 & 20 \\
1943 & 50 & 62 & 160 & \\
\hline
\end{tabular}

1982 system (he was born before 1934) and the second by the 1993 reform. The first one has to contribute ten supplementary quarters (2.5 years) to be entitled to a full pension and if he retires at age 62 his replacement rate is reduced by 2.5 percentage points $(\alpha \times \delta=2 \times 1.25=2.5)$. The second senior, affected by the reform has to contribute 20 supplementary quarters for a full pension and if he retires at age 62, his replacement rate is reduced by 15 percentage points $(\alpha \times \delta=12 \times 1.25=15)$.

This reform thus raised the incentive to work longer before the age of 65 and reduced the pension level, which, in turn, reduced the replacement rate. ${ }^{10}$ It was implemented gradually, as shown in Table 1, which allows for a detailed evaluation of this reform.

Bozio (2011) estimates the effects of the increase in the number of contribution quarters on working lives by measuring the elasticity of the pension drawing age to the contribution period. This survey was conducted on the Cross-Sample of Pension Scheme Beneficiaries (Echantillon Inter-régimes des retraités, i.e. EIR) and National Pension Fund for Salaried Workers (Caisse Nationale d'Assurance Vieillesse, i.e. CNAV) administrative data. As mentioned above, there is heterogeneity in treatment, which enables an estimate of the impact of an increase in the number of contribution quarters on the pension drawing

\footnotetext{
${ }^{10}$ The replacement rate for the above-studied individual would then be: $P / \omega_{r}=\tau^{\prime} \times \min \left(1, \frac{d}{150}\right)=(0.5-0.0125 \times 12) \times$ $140 / 150=0.32$ (if we only take into account the required years of contribution).
} 
1) Senior who has to contribute 150 quarters for FP (1982 system) and has contributed 140 at 60 :

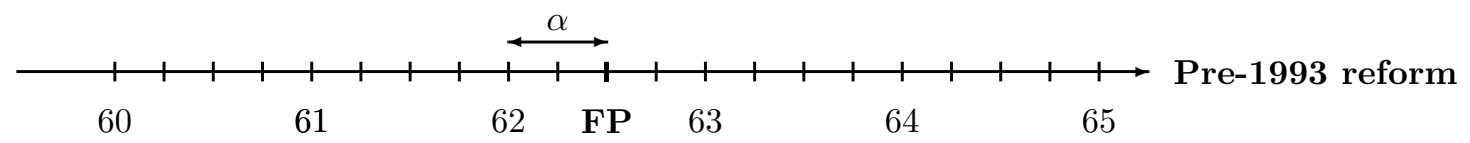

2) Senior who has to contribute 160 quarters for FP (1993 system) and has contributed 140 at 60 :

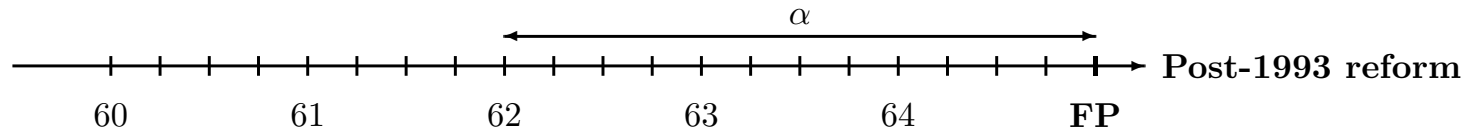

Notes: $\alpha=\min (4 \times(65-a), D-d)$ in equation 3 with a $=62, \mathrm{~d}=140, \mathrm{D}=150$ in the first case and $\mathrm{D}=160$ in the second one. Thus, $\alpha$ is the number of additional quarters needed for FP (Full Pension).

Figure 1: The effect of the 1993 reform for a senior who retires at 62 years old.

age. Bozio (2011) shows that one extra quarter in contributions (required for full pension entitlement) increases the retirement age. A survey conducted by Bridenne and Brossard (2008) of National Pension Fund for Salaried Workers (CNAV) administrative data finds that the pension drawn by individuals who retired between 1994 and 2003 was lower than it would have been without the reform. This shortfall widened with each cohort over the reform period. These parameter effects combined with a pension adjustment effect, which increased with each year of pension payment. The 1993 reform made the index-linking of pensions to inflation official. All in all, therefore, pensions fell a total of $8 \%$ between 1994 and 2003. The combined parameter and index-linking changes had a significant impact on general scheme pension levels.

\section{Data}

We use a French database which is the Health Barometer (Baromètre Santé) conducted every five years by INPES (Institut National de Prévention et d'Education pour la Santé). It contains information on respondents' knowledge and opinions about their health and health-related behaviors. We use the 2005 survey $(n=30,514) .{ }^{11}$ Individuals were affected by the 1993 reform between 2 and 11 years before the 2005 survey depending on the generation, i.e. the 1934 generation was affected in 1994, the 1935 generation in 1995 and so on, through to 2003 for the 1943 generation. ${ }^{12}$

\footnotetext{
${ }^{11}$ Information differs from one survey wave of the Health Barometer (Baromètre Santé) to the next. Some information in the 2005 wave is not included in the previous and following waves. Information on the sector of work is not included in other survey waves. In the 2000 wave, we do not know the sector in which the 2000 wave pensioners used to work.

${ }^{12}$ In 1997, Prime minister Alain Juppé attempted to implement a reform in the public sector, but had to beat a retreat due to a rash of strongly supported strikes all over the country. François Fillon, as Minister of Social Affairs, managed to push through a similar reform in the public sector in 2003 with gradual implementation starting to the generation 1944 . In
} 
Health measures Beyond the medical dimension, Sen (2002) considers health as essential to thrive. Three dimensions are generally highlighted (Blanchet et al., 2007): the medical dimension which considers health as a physiological or psychical norm; the functional dimension which defines health as a capacity to blossom in a social environment and a subjective measure which focuses on the perception of the individual on their health state. We define health using the functional dimension. The Baromètre Santé data contain highly specific questions on mental health, social life and capacity for daily tasks (physical health), used to build the Duke Health indicators, based on self-reported, yet accurate information on the state of respondents' health. The Duke Health Profiles used as health measures, are built on a 17-item generic questionnaire-based on self-report items. ${ }^{13}$ Our definition of health is thus multidimensional: it includes perceived health, self-perception of mental, physical health and social life. We focus on four positive measures of health (physical, mental, perceived health and social life). Table 2 shows how each score is built (we focus on 16 self-reported items). People have three possible choices which are coded as 0,1 or 2 . Answers are reported with respect to their increased quality in terms of health. Duke Health Profiles equals 100 if the individual is in very good health, and 0 if the individual is in bad health (for health measures). For instance, the score of physical health is calculated by multiplying by 10 the sum of the points obtained at each question relative to physical health (questions 8,9,10,11 and 12), the score equals 100 if individual is in very good health $(2+2+2+2+2) \times 10$. The score of perceived health equals 100 if the individuals replies "yes exactly" to the affirmation "I am basically a healthy person".

We also have information on age, gender, years of education, household size, children or not, marital status, household income (by brackets), education and regional areas.

\section{Empirical Strategy}

Difference-in-Differences approach We examine the shift in health scores (i.e. Duke Health Profiles) to identify the 1993 reform effect on individual health in comparing the difference in health between the private and public sectors since the latter was not affected

2003 , there was a creation of the possibility to retire for people who had started to work early (between 14 and 17 years old). They can retire between 56 and 59 years old. Our baseline sample is not affected by this reform, in addition $92 \%$ of our sample is retired.

${ }^{13}$ The Duke Health Profiles are built by Duke University researchers and are validated by the French Health Ministry in its research program Programme Hospitalier de Recherche Clinique du Ministère de la Santé. The Duke health profiles measures health following the three major WHO (World Health Organization) dimensions: physical, mental and social wellbeing. In addition, it provides an overall general health measure to englobe these three dimensions, a separate perceived health measure to indicate the individual assessment of health status, and a sub-scale for self-esteem. Dysfunction is indicated by separate measures for anxiety, depression, pain and disability (Parkerson et al., 1990). 
Table 2: Duke Health Profiles

\begin{tabular}{|c|c|c|c|c|c|}
\hline & $\begin{array}{l}\text { Self-description } \\
(0=\text { not at all, } 1=\text { somewhat }, 2=\text { yes exactly })\end{array}$ & $\begin{array}{l}\text { Perceived } \\
\text { health }\end{array}$ & $\begin{array}{c}\text { Physical } \\
\text { health }\end{array}$ & $\begin{array}{l}\text { Mental } \\
\text { health }\end{array}$ & $\begin{array}{c}\text { Social } \\
\text { life }\end{array}$ \\
\hline 1 & I like who I am & & & 10 & \\
\hline 2 & I am an easy person to get along with & & & & 10 \\
\hline 3 & I am basically a healthy person & 50 & & & \\
\hline 4 & I give up too easily & & & 10 & \\
\hline 5 & I have difficulty concentrating & & & 10 & \\
\hline 6 & I am happy with my family relationships & & & & 10 \\
\hline 7 & $\begin{array}{l}\text { I am comfortable being around people } \\
\text { Today would you have any physical } \\
\text { trouble or difficulty: } \\
(0=\text { a lot, } 1=\text { some, } 2=\text { none })\end{array}$ & & & & 10 \\
\hline 8 & Walking up a flight of stairs & & 10 & & \\
\hline 9 & $\begin{array}{l}\text { Running the lenght of a football field } \\
\text { During the past week how much } \\
\text { trouble have you had with: } \\
(0=\text { a lot, } 1=\text { some, } 2=\text { none })\end{array}$ & & 10 & & \\
\hline 10 & Sleeping & & 10 & & \\
\hline 11 & Hurting or aching in any part of your body & & 10 & & \\
\hline 12 & Getting tired easily & & 10 & & \\
\hline 13 & Feeling depressed or sad & & & 10 & \\
\hline 14 & $\begin{array}{l}\text { Nervousness } \\
\text { During the past week how often did you } \\
(0=\text { none, } 1=\text { some }, 2=\mathrm{a} \text { lot })\end{array}$ & & & 10 & \\
\hline 15 & $\begin{array}{l}\text { Socialize with other people } \\
\text { (talk or visit with friends or relatives) }\end{array}$ & & & & 10 \\
\hline 16 & $\begin{array}{l}\text { Take part in social, religious or recreation activities } \\
\text { (meetings, church, movies, sports, parties) }\end{array}$ & & & & 10 \\
\hline
\end{tabular}

Note : Answers are reported as 0,1 or 2 with respect to their increased quality in terms of health (some questions are formulated negatively, the coding takes into account this inversion. Duke Health Profiles equals 100 if the individual is in very good health, and 0 if the individual is in bad health. For instance, the score of physical health is calculated by multiplying by 10 the sum of the point obtained at each question relative to physical health (questions 8,9,10,11 and 12), the score equals 100 if the individual is in very good health $((2+2+2+2+2) \times 10)$. In the same way, the score of perceived health is calculated by multiplying by 50 the point obtained at question 3 , the score equals 100 if the individual answers yes exactly to the affirmation "I am in good health" $(2 \times 50)$. 
by the reform. This approach is a difference-in-differences method based on birth cohorts instead of time spans since the reform impact depends on the year of birth.

We identify a causal effect of the pension reform under the following assumption: without the reform, differences between generations treated and untreated individuals would have been the same in the public and private sectors. Thus, we assume that seniors, in a given sector, have not experienced other shocks that could affect their health.

Private and public sectors in France are structurally different but there are very few reasons why seniors health between sectors would be different according to the birth cohort. One difference between these sectors is about pre-retirement which only concerns the private sector ${ }^{14}$, however, pre-retirement rules have changed a lot before the 1990's, but not for generations retiring after 1998 and for generations who are concerned by the 1993 reform.

We assume that people did not migrate from private to public sectors (due to the reform), thus it follows that there is no selection bias. Seeing as there is no valid reason for seniors at near-retirement age to change pension system, we can rule out this possibility. According to the 2005 French Labor Force Survey (Enquête Emploi), only very few people moved from the private to the public sector before retirement.

The treatment is heterogeneous between cohorts in the private sector. Individuals born between 1934 and 1943, i.e. treated individuals, have to contribute 5.5 supplementary quarters on average to have a full pension, compared to individuals born before 1934, i.e. non-treated individuals. The pension amount of treated individuals are computed on 5.5 supplementary earnings years (on average), compared to untreated individuals. The DD estimator measures the difference in health between people affected by the reform (treated) and those unaffected (non-treated) between the private sector and the public sector.

We estimate:

$$
Y_{i}=\beta_{0}+\beta_{1} T_{i}+\beta_{2} P_{i}+\beta_{3} T_{i} \times P_{i}+\beta_{4} X_{i}+u_{i}
$$

where $Y_{i}$ is the health status of an individual $i$ (Duke health scores described in Table 2), $T_{i}$ is a dummy variable taking value 1 if individual is treated (i.e., born in 1934 and afterwards) and value 0 if non-treated (i.e., born before 1934). $P_{i}$ is a dummy variable taking value 1 if individual is/was in the private sector and value 0 if individual is/was in

\footnotetext{
${ }^{14}$ Pre-retirement was created in 1972 with an agreement introducing a guarantee of resources for workers aged 60 to 64 in order to protect them against unemployment. Workers over 60 who lost their job can receive a replacement income (up to $70 \%$ of their previous wage) until they reach the age of retirement.
} 
the public sector. $X_{i}$ is a set of controls (including age, age $^{2}$, gender, years of education, household size, children or not, marital status, income, education and regional area). Finally, $u_{i}$ denotes the error term.

The estimator $\beta_{3}$ identifies a causal effect of the pension reform under the following assumption: without the reform, differences between the generations studied would have been the same in the public and private sectors. We conduct placebo tests i) on older individuals who are not impacted by the reform, ii) on younger individuals who are impacted by the reform in the same way.

There may be a cohort effect on health. For instance people born between the Second World War may be in bad health conditions because of malnutrition during childhood. People impacted by the reform may be in worst health because generation 1939 to 1943 are born during the Second World War, using the public sector as a control group enables to control for cohort effects (treated people in the control group are born during the WW II too). As a robustness check, we rerun our regressions for people born before the Second World War (between 1929 and 1938), our results are virtually unchanged (Table A4 in Appendix). ${ }^{15}$

Descriptive statistics We include all individuals born between 1928 and 1943 in our baseline analysis ( $\mathrm{n}=4,619$ see Table A1 in Appendix). As the health outcomes, i.e. Duke health profiles, are sometimes missing, we include all possible observations for each outcome to maximize sample size. Approximately $70 \%$ of our sample is or was in the private sector (30\% in the public sector), $92 \%$ are retired. This proportion is the same in the public and the private sector. ${ }^{16}$

As descriptive statistics, we compare means of health in each sector, for treated individuals (born in 1934 and after, who are affected by the reform in the private sector) and untreated individuals (born before 1934, who are not affected) in the main sample (people born between 1928 and 1943). If we compare these two groups directly, treated individuals are in better health since they are younger, the health status is negatively associated with age (Figure 2). We have to find a strategy to approximate the health difference (between treated and untreated) which we would have been observed without the reform. As the 1993 reform concerns the private sector only, we use a difference-in-differences method to

\footnotetext{
${ }^{15}$ There is no distinction between age and cohort effects, due to the cross-sectional nature of the data, we assume that the cohort/age effect on health would have be the same between the private and the public sector in the absence of reform.

${ }^{16}$ Figure A1 shows the proportion of high-educated people in each sector per birth year, the composition is the same across cohorts. The public sector is higher educated, but the difference is stable across cohorts. To check the presence of composition effects, Table A2 presents the jobs composition in the public sector by group; i.e. untreated (generations 1928-1933) and treated individuals (generations 1934-1943). The proportion in each category is stable between treated and untreated individuals. The difference in means is not significantly different by group.
} 


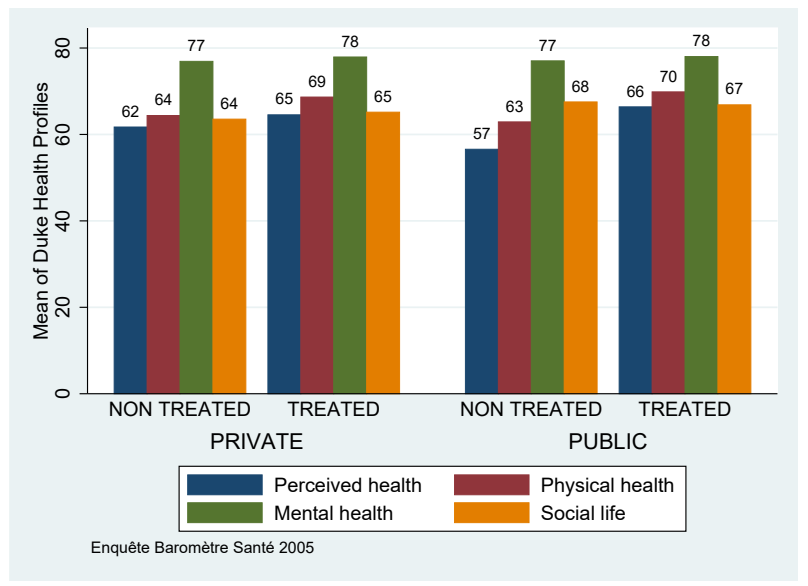

Figure 2: Difference in health for the baseline sample

Table 3: Summary statistics of demographic and health variables for the baseline sample

\begin{tabular}{lccccccc}
\hline \hline & \multicolumn{2}{c}{ All sample } & \multicolumn{2}{c}{ High educated } & \multicolumn{2}{c}{ Low educated } \\
\cline { 2 - 8 } & mean & $\mathrm{N}$ & mean & $\mathrm{N}$ & mean & $\mathrm{N}$ \\
Perceived health & 63.73 & 2986 & 67.85 & 972 & 61.70 & 2014 \\
Physical health & 67.56 & 2965 & 69.92 & 967 & 66.39 & 1998 \\
Mental Health & 77.66 & 2960 & 79.47 & 963 & 76.77 & 1997 \\
Social life & 65.30 & 2931 & 68.72 & 955 & 63.61 & 1976 \\
\hline \hline
\end{tabular}

measure the effect of the reform on health using the public sector as a control group.

The average perceived health score is 63.73 for individuals born between 1928 and 1943 (Table 3). As we expected that the effect of the 1993 pension reform may be heterogeneous according the kind of work, we divide our analysis by educational levels (as a proxy of the social condition). First of all, we notice that less-educated individuals are a majority in France for the generations studied, accounting for approximately $70 \%$ of the sample (i.e. generation 1928 to 1943). ${ }^{17}$ Less educated individuals (i.e. have not obtained the French school-leaving certificate, i.e. baccalauréat) are less healthy whatever the health indicator. The average perceived health score is 61.70 for less-educated people, compared to 67.85 for better-educated people (having qualifications equal to or post French school-leaving certificate, i.e. baccalauréat), low-educated individuals are in poorer physical and mental health compared to highly-educated individuals (Table 3).

\footnotetext{
${ }^{17}$ This is consistent with the Enquête Emploi survey conducted by the French National Institute of Statistics and Economic Studies (INSEE) in 2009 (Clerc et al., 2011).
} 


\section{Results}

\subsection{Main results}

We implement a difference-in-differences strategy in which the public sector is used as a control group. Estimates of Equation 4 are presented in Table $4 .{ }^{18}$ Each line presents the coefficient (resp. standard error and number of observations used in the model) associated with the interaction term $T_{i} \times P_{i}$ for a different health outcome (where $T_{i}$ is the treatment dummy). Our results show a negative effect of the 1993 reform, the health score of perceived health decreases by approximately 7 points for people in the private sector affected by the reform in the whole sample (Panel A). It corresponds to a decrease by approximately $10 \%$ of the score of perceived health (see Table 3). However other health indicators are not significant at standard level. Thus, we find that the 1993 pension reform was detrimental to perceived health.

This impact probably differs with the type of work. In particular, work may be more strenuous for unskilled workers. We approximate the skill levels of their work through their education. We divide the population into two groups: high school graduates and non-graduates (i.e. have not obtained the French school-leaving certificate, baccalauréat). The results of our estimations are shown in Table 4, Panel B gathers less-educated people, Panel C gathers highly-educated people. We rerun the same analysis with clustered standard errors that take into account the potential correlation within the same cohort cell, results are more significant (see Table A6 in Appendix). ${ }^{19}$

We notice that high school graduates are a minority in France for the generations studied, accounting for just 30\% of the baseline sample (i.e. generation 1928 to 1943). This is consistent with the Enquête Emploi survey conducted by the French National Institute of Statistics and Economic Studies (INSEE) in 2009 (Clerc et al., 2011). The main trend found by our first estimation is thus probably due to less-educated individuals (approximately $70 \%$ of the main sample).

Table 4 shows a negative effect of the 1993 reform, the score of perceived health decreases by approximately 13 points (i.e. $20 \%$, see Table 3) for less-educated people affected by the reform in the private sector, relatively to the public sector (Panel B). The score of physical health decreases by approximately 5 points (i.e. $7 \%$, see Table 3 ), this coefficient is significant at 10\% (without control), at 15\% (with controls), however the

\footnotetext{
${ }^{18}$ The detail for the all regression is presented in Table A3 in Appendix.

${ }^{19}$ We rerun a sensitivity analysis without including income as control (because of a potential endogeneity issue). Our results are virtually unchanged.
} 
Table 4: Difference-in-Differences analysis - Baseline analysis

\begin{tabular}{|c|c|c|c|c|c|c|}
\hline \multicolumn{7}{|c|}{ People born between 1928 and 1943} \\
\hline & Without control & s.e. & $\mathrm{N}$ & With controls & s.e. & $\mathrm{N}$ \\
\hline \multicolumn{7}{|c|}{ Panel A - All sample } \\
\hline Perceived health & $-6.987 * *$ & $(3.539)$ & 2986 & $-7.243^{*}$ & $(4.201)$ & 2280 \\
\hline Physical health & -2.666 & $(2.128)$ & 2965 & -3.543 & $(2.408)$ & 2267 \\
\hline Mental health & 0.016 & $(2.045)$ & 2960 & -0.755 & $(2.334)$ & 2266 \\
\hline Social life & 2.290 & $(1.879)$ & 2931 & 2.322 & $(2.138)$ & 2248 \\
\hline \multicolumn{7}{|c|}{ Panel B - Low-educated } \\
\hline Perceived health & $-13.197 * * *$ & $(5.047)$ & 2014 & $-12.876^{* *}$ & $(5.759)$ & 1574 \\
\hline Physical health & $-5.470^{*}$ & $(3.212)$ & 1998 & -5.756 & $(3.533)$ & 1564 \\
\hline Mental health & -3.530 & $(3.367)$ & 1997 & -4.944 & $(3.563)$ & 1565 \\
\hline Social life & -0.047 & $(2.653)$ & 1976 & -0.481 & $(3.070)$ & 1552 \\
\hline \multicolumn{7}{|c|}{ Panel C - High educated } \\
\hline Perceived health & -2.582 & $(5.517)$ & 972 & -2.352 & $(7.146)$ & 706 \\
\hline Physical health & -1.138 & $(3.263)$ & 967 & -0.333 & $(3.869)$ & 703 \\
\hline Mental health & 1.089 & $(2.816)$ & 963 & -0.012 & $(3.266)$ & 701 \\
\hline Social life & 4.262 & $(2.998)$ & 955 & 3.806 & $(3.400)$ & 696 \\
\hline
\end{tabular}

intensity of the coefficient is identical meaning that we may have a power problem in the second estimation (with controls).

The parameters reported in Table 4 for social life scores are all non-significant, however, they are positive for Panel A (all sample) and Panel C (highly educated people). The same is observed in Tables in Appendix. These results seem to be driven by high-educated individuals. Thus, it cannot be excluded that staying at work for longer periods (delaying retirement) affects individuals' social life in a favorable way. This result is interesting and could be put in relation with the results obtained in several studies, which found a positive effect of delaying retirement on cognitive functioning (Bingley and Martinello, 2013; Bonsang et al., 2012; Mazzonna and Peracchi, 2012; Rohwedder and Willis, 2010). ${ }^{20}$

\subsection{Potential mechanisms}

Behaghel et al. (2016) illustrate the observed evolution of pathway probabilities of retirement. It appears that after the 1993 reform, unemployment and early retirement pathway increased dramatically, as well as disability among women and low-skilled workers. This could constitute mechanisms to explain the impact of the 1993 reform on health. Unfortunately, we do not have enough information on careers to know the pathway probabilities

\footnotetext{
${ }^{20}$ However, this effect is not significant whatever the specifiction.
} 
in our database.

The 1993 reform could have an impact on health through two different ways. Firstly, there may be an income effect. De Grip et al. (2009) show that an unexpected decrease in replacement rates in Dutch pension system implies an increase in depression among seniors. The reform may reduce income and diminish purchasing power, as a consequence health consumption may, in turn, decrease. This decrease could have a negative impact on health. ${ }^{21}$ Bridenne and Brossard (2008) show an $8 \%$ decrease of pensions between 1994 and 2003 (i.e. for generations 1934 to 1943). Unfortunately, we have information on income brackets only, this is not enough precise to test this hypothesis. Secondly, there may be an activity effect, i.e. an increase in working life has repercussions on health. Bozio (2011) showed that the reform increased retirement age. We are not able to distinguish between these two effects, the effect on health could be a combination of these two effects.

One might expect that public-sector employees are quite different from private-sector employees. They might be different in terms of health or age profiles violating the main identification assumption. For instance, this could occur if the health of people in the private sector starts to decline earlier than those of the public-sector. In order to check this hypothesis, we consider the health differential between sectors between cohorts who have homogeneous retirement constraints. We rerun our regressions (cf. Equation 4) for people who are unaffected by the 1993 reform (people born between 1928 and 1933, cf. Table 1). We conduct placebo tests i) on younger individuals ii) on older individuals who have homogeneous retirement constraints. ${ }^{22}$

\subsection{Robustness checks}

\subsubsection{Placebo tests}

As robustness checks, we consider health differentials between sectors between cohorts who have homogeneous retirement constraints: i) we rerun our regressions (cf. Equation 4) for people who are not affected by the 1993 reform (people born between 1928 and 1933,

\footnotetext{
${ }^{21}$ Snyder and Evans (2006) exploit an exogenous change in the US Social Security system which offered to adjacent cohorts very different levels of pension benefits. They show that the higher-income group has a statistically significantly higher mortality rate, contradicting the literature results.

${ }^{22}$ For many cohorts in the study the observation period (2005) is far away from the potential treatment (reform) and selective mortality might be an issue especially for the older cohorts. For instance, people born in 1930 were 75 years old in 2005. So even assuming the identification assumption holds, the effect of retirement might be bias by selective mortality. Public sector workers may live slightly longer than private sector workers. We are unable to correct for this bias, however we may overestimate our results since people in the private sector may be more resistant. As a robustness check, we consider health differential between sectors between cohorts who have homogeneous retirement constraints for older cohort unaffected by the 1993 reform (people born between 1928 and 1933, cf. Table 5). We find no significant effect.
} 
cf. Table 1); ii) we rerun our regressions (cf. Equation 4) for people who are affected in the same way by the reform (people born between 1960 and 1975). We conduct placebo tests on older individuals ii) on younger individuals. There should be no $\beta_{3}$ effect.

We estimate Equation 4 for people born between 1928 and 1933, who are not affected by the reform, considering the generation 1931 as the first generation affected by an hypothetical reform, i.e. $T_{i}$ is a dummy variable taking value 1 if an individual is treated (born in 1931, 1932 and 1933) and value 0 if non-treated (born before 1931). $P_{i}$ is a dummy variable taking value 1 if the individual is in the private sector and 0 if the individual is in the public sector. Table 5 shows that, at a given age, the difference between younger generations and older generations is the same in the private and public sector (if the threshold is the 1931 generation). This confirms that the health differential between the cohorts between the two sectors is due to policy differentials.

We estimate Equation 4 for people born between 1960 and 1975, who are affected in the same way by the reform, considering the generation 1970 as the first generation affected by an hypothetical reform, i.e. $T_{i}$ is a dummy variable taking value 1 if an individual is treated (born in 1970 and afterwards) and value 0 if non-treated (born before 1970). $P_{i}$ is a dummy variable taking value 1 if the individual is in the private sector and 0 if the individual is in the public sector. ${ }^{23}$ Results are presented in Table 6. Each line presents the coefficient (resp. standard errors and number of observations in the model) associated with the interaction $T_{i} \times P_{i}$ for a different health indicators. Our results show that, at a given age, the difference between younger generations and older generations is the same in the private and public sector (if the threshold is the 1970 generation). This confirms that the health differential between the cohorts between the two sectors is due to policy differentials.

Overall, these placebo tests provide evidence that the negative impact of health for generation born in 1934 and afterwards is explained by the 1993 reform, this effect is driven by the less educated individuals.

\subsubsection{The reform design}

The reform does not affect the treated cohorts uniformly. In other words, the retirement disincentive increases over time, simultaneously as the distance to the treatment decreases.

\footnotetext{
${ }^{23}$ In 1997, Prime minister Alain Juppé attempted to implement a reform in the public sector, but had to beat a retreat due to a rash of strongly supported strikes all over the country. François Fillon, as Minister of Social Affairs, managed to push through a similar reform in the public sector in 2003 with gradual implementation starting to the generation 1944 . In 2003, there was a creation of the possibility to retire for people who had started to work early (between 14 and 17 years old). We are sure that people born between 1960 and 1975 are affected in the same way by the 2003 reform.
} 
Table 5: Placebo - Difference-in-Differences analysis for older cohorts (people born between 1928 and 1933, 1928 to 30 versus 1931 to 33 )

\begin{tabular}{lcccccc}
\hline \hline People born between 1928 and 1933 & & & & & & \\
& Without control & se & N & With controls & se & N \\
Panel A - All sample & & & & & & \\
Perceived health & 0.749 & $(6.171)$ & 848 & 8.271 & $(7.885)$ & 613 \\
Physical health & 4.455 & $(3.745)$ & 836 & 6.518 & $(4.420)$ & 606 \\
Mental health & $-7.617^{* *}$ & $(3.484)$ & 842 & -4.248 & $(4.153)$ & 611 \\
Social life & $-5.449^{*}$ & $(3.245)$ & 830 & 0.892 & $(3.898)$ & 604 \\
Panel B - Low-educated & & & & & & \\
Perceived health & 10.624 & $(8.668)$ & 607 & 16.721 & $(10.230)$ & 464 \\
Physical health & 4.420 & $(5.608)$ & 598 & 8.333 & $(5.954)$ & 459 \\
Mental health & -6.938 & $(5.660)$ & 602 & -1.090 & $(6.032)$ & 463 \\
Social life & -4.563 & $(4.547)$ & 595 & -0.870 & $(5.531)$ & 457 \\
Panel C - High-educated & & & & & & \\
Perceived health & -3.594 & $(9.837)$ & 241 & 10.608 & $(16.281)$ & 149 \\
Physical health & 7.115 & $(5.709)$ & 238 & 9.161 & $(8.249)$ & 147 \\
Mental health & -6.201 & $(4.821)$ & 240 & -7.352 & $(6.599)$ & 148 \\
Social life & -2.869 & $(5.218)$ & 235 & -2.397 & $(6.793)$ & 147 \\
\hline \hline
\end{tabular}

Note: robust standard errors in parentheses. P-value $<0.01,{ }^{* *}$ p-value $<0.05,{ }^{*}$ p-value $<0.1$. Controls are treated, private sector, age, age $^{2}$, income, gender, children or not, education, size of the household and marital status and regions of residence.

Table 6: Placebo - Difference-in-Differences analysis for younger cohorts (people born between 1960 and 1975, 1960 to 69 versus 1970 to 75 )

\begin{tabular}{lcccccc}
\hline \hline People born between 1960 and 1975 & & & & & & \\
& Without control & se & N & With controls & se & N \\
Panel A - All sample & & & & & & \\
Perceived health & -2.865 & $(2.042)$ & 5290 & -3.412 & $(2.101)$ & 4812 \\
Physical health & 0.527 & $(1.231)$ & 5281 & 0.336 & $(1.243)$ & 4805 \\
Mental health & 0.159 & $(1.236)$ & 5280 & -0.270 & $(1.233)$ & 4804 \\
Social life & 0.008 & $(1.128)$ & 5251 & -0.316 & $(1.144)$ & 4780 \\
Panel B - Low-educated & & & & & & \\
Perceived health & -5.314 & $(4.340)$ & 2046 & -5.831 & $(4.676)$ & 1858 \\
Physical health & 0.447 & $(2.490)$ & 2039 & -0.726 & $(2.546)$ & 1853 \\
Mental health & 0.410 & $(2.515)$ & 2040 & -1.300 & $(2.588)$ & 1854 \\
Social life & 0.143 & $(2.338)$ & 2030 & -0.890 & $(2.371)$ & 1846 \\
Panel C - High-educated & & & & & & \\
Perceived health & -1.555 & $(2.412)$ & 3244 & -1.747 & $(2.445)$ & 2954 \\
Physical health & 0.539 & $(1.425)$ & 3242 & 0.951 & $(1.438)$ & 2952 \\
Mental health & 0.826 & $(1.454)$ & 3240 & 0.508 & $(1.460)$ & 2950 \\
Social life & -0.658 & $(1.307)$ & 3221 & -0.109 & $(1.368)$ & 2934 \\
\hline \hline
\end{tabular}

Note: robust standard errors in parentheses. ${ }^{* * *} \mathrm{P}$-value $<0.01,{ }^{* *} \mathrm{p}$-value $<0.05,{ }^{*}$ p-value $<0.1,{ }^{\mu}$ p-value $<0.15$ All regressions include treated $\left(T_{i}\right)$ and private sector $\left(P_{i}\right)$. Controls are age, age ${ }^{2}$, income, gender, children or not, education, size of the household and marital status and regions of residence. 
Consequently, the impact on health may depend on the generation. Individuals were affected by the 1993 reform between 2 and 11 years before the 2005 survey depending on the generation, i.e. the 1934 generation was affected in 1994, the 1935 generation in 1995 and so on, through to 2003 for the 1943 generation. However, if we compare the 1933 cohort with that of 1934, the difference in the retirement incentive is rather small (in terms of contribution quarters and reference earning years) while the retirement incentive between 1933 and 1943 cohorts is larger.

We rerun our regressions for generations born between 1929 and 1938, considering a lower bandwidth around the 1934 generation (the first generation to be impacted by the 1993 reform), i.e. we rerun our regressions for 1929 to 1933 generations (which are unaffected by the reform, i.e. untreated) and 1934 to 1938 generations (impacted by the reform, i.e. treated). Table A4 shows the results. In this table we restrict the cohorts in the sample excluding those more affected by the reform (1939 and younger). They are also the first cohorts affected by the reform, i.e. the distance to the treatment ranges between 11 to 7 years. Each line presents the coefficient (resp. standard error and number of observations used in the model) associated with the interaction term $T_{i} \times P_{i}$ for a different health outcome (where $T_{i}$ is the treatment dummy), see Equation 4. Our results confirm a negative effect of the 1993 reform, the health score of perceived health decreases by approximately 8 points for people affected by the reform in the private sector (Panel A, see specification with controls). Thus, our results are virtually the same for generations born 5 years before and after the 1934 threshold, a negative impact on perceived and physical health (-15 and -7 respectively), entirely driven by less-educated individuals (see Panel B, specification with controls). The coefficients are not significantly different compared to those of our baseline analysis. We rerun our regressions by considering a lower bandwidth around the 1934 generation(4 and 3 years) ${ }^{24}$ However, our samples are smaller. We have larger standard errors, so our results are less precise. Nevertheless, the results tend to be the same. Table A5 show a negative effect on physical health 4 and 3 years before and after the 1934 generation. We rerun the same analysis with clustered standard errors that take into account the potential correlation within the same cohort cell, results are more significant (see Table A6 in Appendix). The results are virtually the same in terms of perceived health, meaning that the impact of the reform may be homogeneous. ${ }^{25}$

\footnotetext{
${ }^{24}$ Our results are the same, i.e. a negative effect of the 1993 reform on perceived health and physical health which is significant for low-educated people.

${ }^{25}$ The reform does not affect the treated cohorts uniformly. The intensity of the treatment increase with cohorts (since
} 


\subsubsection{The common trend assumption}

The main assumption of our estimation is that, given the control variables, the only thing that could explain health differentials between cohorts between sectors is due to retirement policies. ${ }^{26}$ The identifying assumption is that the age/cohort profiles would have been the same, up to a constant shift, in the absence of the reform. We check this assumption on pre-reform cohorts (1931 to 1933), not affected by the 1993 reform. Figure 3 shows the evolution of the average of Duke-Health Profiles for pre-reform cohorts for lesseducated individuals (see Figure 3a) and highly-educated individuals (see Figure 3b). ${ }^{27}$ More precisely, the outcome (on the $Y$-axis) corresponds to the average of physical, mental, perceived health and social life, it gathers information contained in Table 2. The evolution of this synthetic indicator is the same between these three pre-reform cohorts. ${ }^{28}$

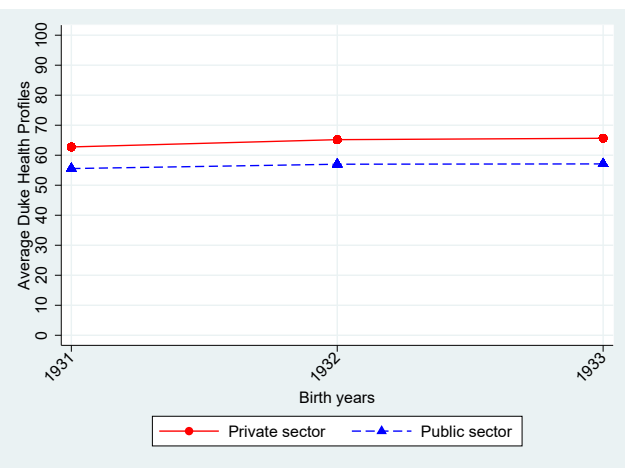

(a) Less-educated individuals

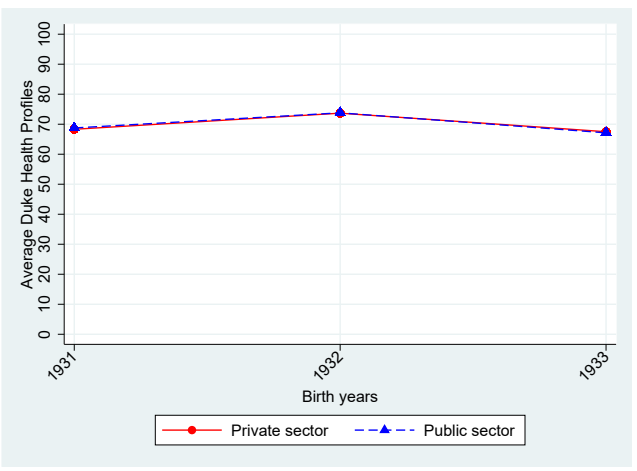

(b) Highly-educated individuals

Note: The outcome (on the $Y$-axis) corresponds to the average of four positive measures: physical, mental, perceived health and social life. It gathers information contained in Table 2.

Figure 3: Common trend - pre-reform cohorts (Duke Health Profiles)

More precisely, Figures 4b and 4d corresponds to the health difference public-private sectors between each cohort (1934-1943) and the 1933 cohort, not affected by the reform (specifications with controls); whereas Figures 4a and 4c correponds to the common trend between 1932 and 1933 (taken as a reference). ${ }^{29}$ Equation 4 is repeated for each cohort taken generation 1933 as control group. The results are virtually the same, i.e. a negative

\footnotetext{
younger cohorts are more affected by the reform). However, the magnitude of the effect is not significantly different across cohorts. Perhaps this is owning to a lack of precision due to the number of observations, which is not large enough per cohort. This could be because the income effect prevails (see Section 5.2). Moreover, the distance to the treatment decrease over time, simultaneously as the retirement disincentive increases. The magnitude of the effect could decrease per cohort, since the first affected generation did not expect the reform. The first generation was impacted 11 years before the 2005 survey, whereas the 1943 generation was impacted 2 years before the 2005 survey. The effects on health could appear later, and more time is needed. Thus, there could be an effect "distance to the treatment" (which may compensate the effect "intensity of the treatment").

${ }^{26}$ Most papers test this assumption by studying other periods.

${ }^{27}$ We divide the sample between less-educated $(62 \%)$ and highly-educated $(38 \%)$, results are virtually the same when we divide the sample as previously (respectively 68 and $32 \%$ ).

${ }^{28}$ Figures A2a and A2b show the difference-in-differences estimation for cohorts impacted by the reform taking generation 1933 as control group.

${ }^{29}$ We focus on outcomes which are significant in Table A4 and A5.
} 


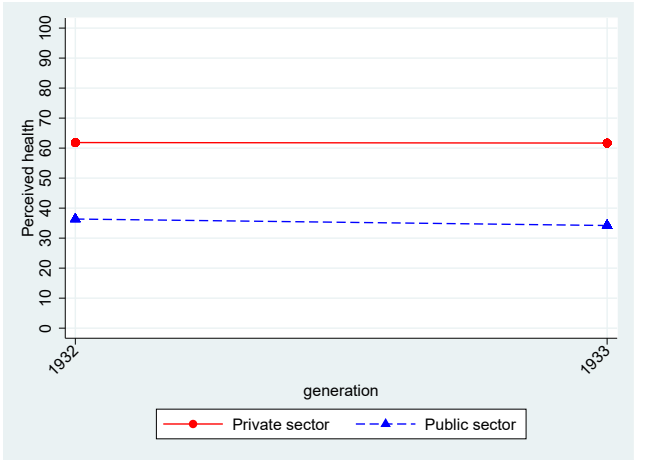

(a) Common trend on perceived health

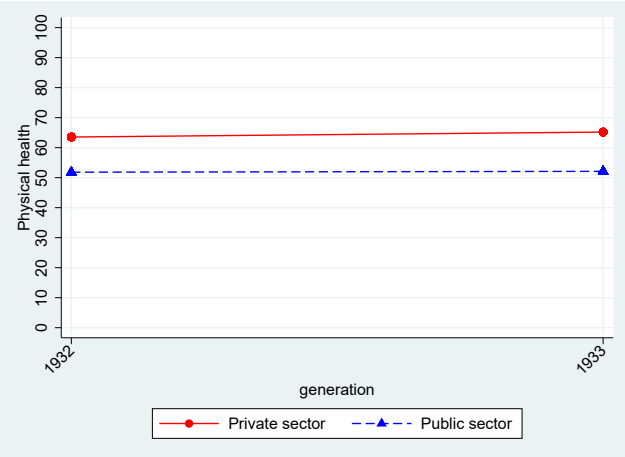

(c) Common trend on physical health

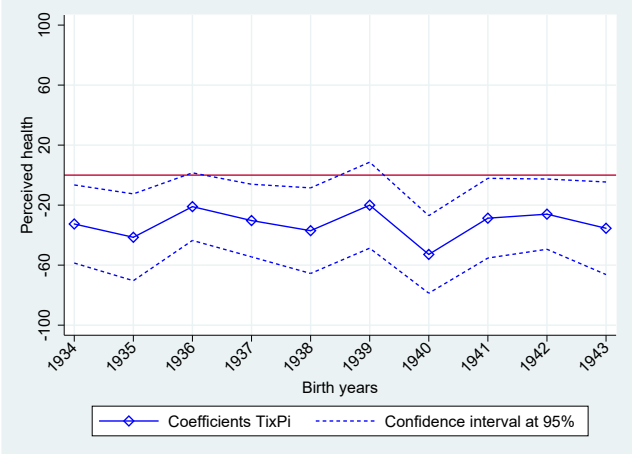

(b) DiD on perceived health

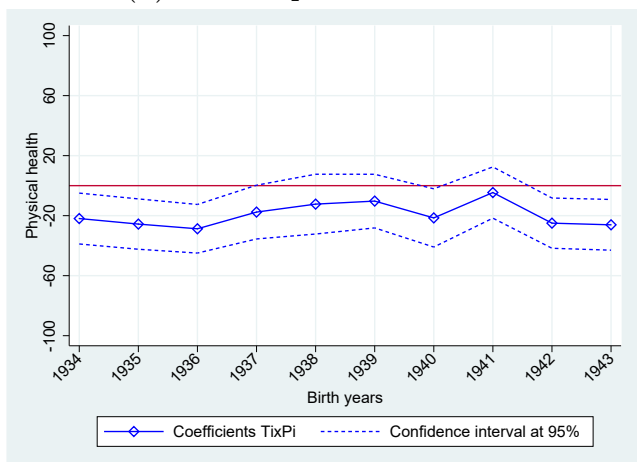

(d) DiD on physical health

Note: Figure 4a and 4c present the common trend between generations 1932 and 1933, not affected by the reform (without control). In Figure 4b and 4d, Equation 4 is repeated for each cohort taken generation 1933 as control group. All regressions include treated $\left(T_{i}\right)$ and private sector $\left(P_{i}\right)$. For the first coefficient $T_{i}=1$ if the individual is born in 1934, 0 if the individual is born in 1933. Controls are income, gender, numbers of children, education, size of the household and marital status and regions of residence.

Figure 4: Reform impact on health scores between cohorts (less-educated individuals)

effect on perceived and physical health for low-educated individuals. We add a health indicator: good health or not as a proxy of SRH (self-rated health), which is an indicator often used in the literature. Respondents answer to the question: "I am basically an healthy person" (not, somewhat, yes exactly). We attribute the value 1 to the variable if the individual answers is "yes exactly" to this question, 0 otherwise. This indicator confirms the results based on Duke Health Profiles for all our specifications, we present the DiD Figure A3b in Appendix (common trend is presented in Figure A3a). 


\section{Conclusion}

As a conclusion, a difference-in-differences approach can provide a good estimate for retirement reform influences on health. We contribute to the literature in several ways. We develop an identification strategy which is different in spirit from those previously employed in the literature. We consider the effect of a French pension reform on health, whereas previous studies use eligibility ages for pension benefits as instrumental variables for retirement across states or country. This ensures that our results cannot be biased by country-specific or state-specific effect.

Health measures in this paper are subjective, meaning that they may suffer from a self-reported bias. Nevertheless, clinical validity of the Duke Health Profiles was checked by Parkerson et al. (1990), testing the correlation and coherence between the Profiles and clinical problems. ${ }^{30}$ Basically, we used Duke Health Profiles for two reasons. First, they give a global view of individual's health taking into account mental, physical, perceived health and social well-being. Secondly, they are medically validated (Parkerson et al., 1990).

We find that individuals who was impacted by the 1993 reform consider themselves less healthy. Less educated individuals seem to be strongly affected by the 1993 reform especially in terms of physical health. Conversely, highly educated individuals are virtually unaffected. This may be due to the fact that with greater incentives to work, people stay on the labor market despite being tired, which decreases the average health of workers. In the latter case, the difference between the effective and the desired amount of work is detrimental to health (Bassanini and Caroli, 2015). The 1993 reform could have an impact on health through two different channels : i) there may be an income effect (i.e. an income decrease has repercussions on health); ii) there may be an activity effect (i.e. an increase in working life has repercussions on health). Our data do not allow us to go beyond mere speculations on this matter.

The external validity of our findings depends on the similarity between the 1928-1943 cohorts and the current cohorts of pensioners. However, this finding raises the question of the long-term efficiency of retirement reforms. First, they may have a detrimental effect on people's health. Second, they may increase health inequality since less educated people are more affected by the negative effects of the reforms.

\footnotetext{
${ }^{30}$ However, their demonstration of clinical validity is hampered by the relatively small size of the data set, the presence of a large variety of health problems and extensive co-morbidity and the benign nature of most of the health problems. In addition, health status should be monitored over time to test the effectiveness of the Duke Health Profiles to detect changes of clinical relevance and to determine precision in terms of how small a change can be measured.
} 


\section{Bibliography}

Aliaj, A., X. Flawinne, A. Jousten, S. Perelman, And L. Shi (2016): "Old-age employment and hours of work trends: empiricial analysis for four European countries," IZA Journal of European Labor Studies.

Bamia, C., A. Trichopoulous, and D. Trichopoulous (2007): "Age at retirement and mortality in a general popualtion sample: The Greek EPIC Study." American Journal of Epidemiology, 167, 561-569.

Bassanini, A. And E. Caroli (2015): "Is Work Bad for Health? The Role of Constraint vs Choice," Annals of Economics and Statistics, 13-37.

Behaghel, L., D. Blanchet, And M. Roger (2016): "Retirement, Early Retirement and Disability: Explaining Labor Force Participation after Fifty-Five in France," in Wise D. (Ed.), Social Security Programs and Retirement around the World: Disability Insurance Programs and Retirement, University of Chicago Press, 251-284.

Berniell, I. And J. Bietenbeck (2017): "The Effect of Working Hours on Health," IZA Discusion Paper.

Bingley, P. And A. Martinello (2013): "Mental retirement and schooling," European Economic Review, 63, 292-298.

Blanchet, D. And T. Debrand (2008): "The Sooner, the Better? Analysing for Preferences for Early Retirement in European Countries." IRDES Working Papers, DT13.

Blanchet, D., T. Debrand, P. Dourgnon, and A. Laferrere (2007): "Santé, vieillissement et retraite en Europe," Economie et Statistique, 403-404, 3-18.

Bloemen, H., S. Hochguertel, And J. Zweerink (2017): "The causal effect of retirement on mortality : Evidence from targeted incentives to retire early." forthcoming Health Economics.

Bonsang, E., S. Adam, And S. Perelman (2012): "Does Retirement Affect Cognitive Functionning?" Journal of Health Economics, 31, 490-501.

Bound, J. And T. Waidmann (2008): "Estimating the Health Effects of Retirement," University of Michigan Retirement Research Center, Working Papers, 168.

Bozio, A. (2008): "Impact evaluation of the 1993 French pension reform on retirement age," Pensions: An International Journal, 13, 207-212. 
(2011): "Mesurer l'impact de l'augmentation de la durée d'assurance: le cas de la réforme des retraites de 1993." Economie et statistique, 441-442.

Bradford, L. P. (1979): "Can you survive your retirement?" Harvard Business Review, $57(3), 103-109$.

Bridenne, I. And C. Brossard (2008): "Les effets de la réforme de 1993 sur les pensions versées par le régime général," Retraite et société, 54.

Brockmann, H., R. Muller, and R. Helmert (2009): "Time to retire - time to die? A prospective cohort study of the effects of early retirement on long-term survival," Social Science and Medicine, 69, 160-164.

Caroli, E., C. Lucifora, And D. Vigani (2016): "Is there a Retirement-Health Care utilization puzzle? Evidence from SHARE data in Europe," Working paper Series Università Cattolica del Sacro Cuore.

CARP, F. M. (1967): "Retirement crisis." Science, 157, 102-103.

Clerc, M. C., O. Monso, And E. Pouliquen (2011): "Les inegalités entre générations depuis le baby-boom." Dossier, l'économie française.

Coe, N. And M. Lindeboom (2008): "Does Retirement Kill You? Evidence from Early Retirement Windows." Tilburg University, Center for Economic Research, 93.

Coe, N. B. And G. Zamarro (2011): "Retirement Effects on Health in Europe." Journal of Health Economics, 30, 77-86.

Eibich, P. (2015): "Understanding the effect of retirement on health: Mechanisms and heterogeneity," Journal of Health Economics, 63, 1-12.

Eisdorfer, C. AND F. Wilkie (1977): "Stress, disease aging and behavior." In James E. Birren and K. Warnere Shaie (eds) Handbook of the Phsychology of Aging. New York: Van Nostrand, Reinhold., 251-275.

Ekerdt, D., J. Bosse, And J. LocAstro (1983): "Claims that retirement improves health." Journal of Gerontology, 38, 231-236.

GodARD, M. (2016): "Gaining weight through retirement? Results from the SHARE survey." Journal of Health Economics, 45, 27-46. 
Hagen, J. (2018): "The causal effect of retirement on mortality : Evidence from targeted incentives to retire early." Journal of Population Economics, 31, 193-234.

Hernaes, E., S. Markussen, J. Piggott, and O. L. Vestad (2013): "Does retirement age impact mortality?" Journal of Health Economics, 32, 586-598.

KalwiJ, A. And F. Vermeulen (2008): "Health and Labour Force Participation of Older People in Europe: What Do Objective Health Indicators Add to the Analysis?" Health Economics, 17(5), 619-638.

Kunn, A., W. J.P., And Z. J. (2010): "Fatal attraction? Access to early retirement and mortality." Institute for the Study of Labor (IZA) Discussion Paper 5160.

Lindeboom, M. And M. Kerkhofs (2004): "Health and work of the elderly: subjective health measures, reporting errors and endogeneity in the relationship between health and work." Journal of Applied Econometrics, John Wiley and Sons, Ltd., 24(6), 10241046.

Macbride, A. (1976): "Retirement as a life crisis: myth or reality?" Canadian Psychiatric Association Journal, 72, 547-556.

Mahieu, R. And D. Blanchet (2004): "Estimating models of retirement behavior on French data," in Gruber, J. and D. Wise (Ed.), Social Security Programs and Retirement around the World: Micro Modelling of Retirement Incentives in the World, University of Chicago Press and NBER, 235-284.

Mazzonna, F. And F. Peracchi (2012): "Ageing, cognitive abilities and retirement," European Economic Review, 56, 691-710.

(2017): “Unhealthy retirement?" Journal of Human Resources, 52, 128-151.

Pagan, R. (2011): “Ageing and Disability : Job Satisfaction Differentials across Europe." Social Science and Medicine, 72(2), 206-215.

Parkerson, G., W. Broadhead, and C. Tse (1990): "The Duke Health Profile: A 17-Item Measure of Health and Dysfunction," Medical Care, 28, 1056-1072.

Rohwedder, S. And R. J. Willis (2010): "Mental Retirement." Journal of Economic Perspectives, American Economic Association., 24, 119-38. 
Salem, M., D. Blanchet, A. Bozio, And M. Roger (2012): "Labor force participation by the elderly and employment of the young: The case of France," in Gruber, J. and D. Wise (eds.), Social Security Programs and Retirement around the World: The Relationship to Youth Employment, NBER and University of Chicago Press, 119-146.

SEn, A. (2002): "Health : Perception versus Observation." British Medical Journal, 324, 860-861.

Sheppard, H. L. (1976): "Work and Retirement." Handbook of Aging and the Social Sciences.

SNyder, S. And W. Evans (2006): "The Effect of income on Mortality: Evidence from the Social Security Notch," Review of Economics and Statistics, 88, 482-495.

Soulat, L., S. Cambier, And E. Poujardieu (2014): "Réformes des retraites et évolution des âges de départ à la CNRACL : un éclairage sur les fonctionnaires hospitaliers et territoriaux sédentaires," Questions Retraite et Solidarité. Les Cahiers, Direction des retraites et de la solidarité.

Walraet, E. And R. Mahieu (2012): "Simulating retirement behavior: The case of France," in Gruber, J. and D. Wise (eds.), Social Security Programs and Retirement Around the World: Fiscal Implications for Reform, University of Chicago Press and NBER, 155-200. 


\section{Appendix}

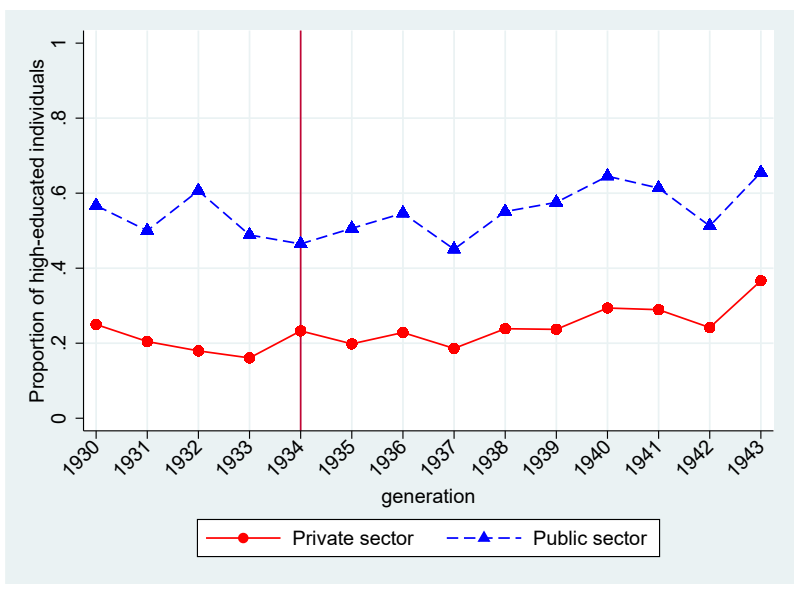

Figure A1: Proportion of highly-educated people by sector

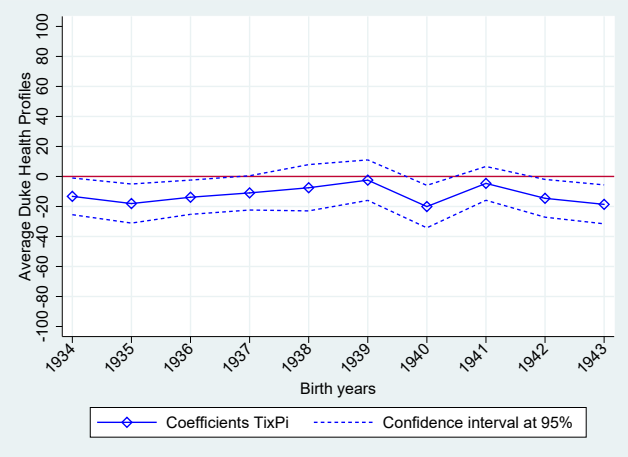

(a) Less-educated individuals

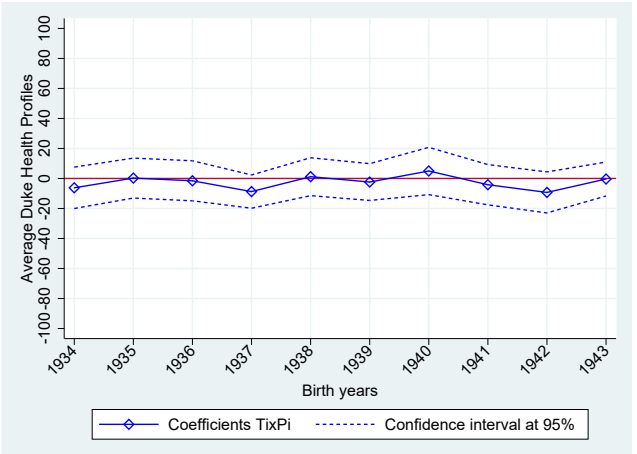

(b) Highly-educated individuals

Note: The outcome (on the $Y$-axis) corresponds to the average of four positive measures: physical, mental, perceived health and social life. It gathers information contained in Table 2. In Figures A2a and A2b, Equation 4 is repeated for each cohort taken generation 1933 as control group. All regressions include treated $\left(T_{i}\right)$ and private sector $\left(P_{i}\right)$. For the first coefficient $T_{i}=1$ if the individual is born in 1934, 0 if the individual is born in 1933. Controls are income, gender, numbers of children, education, size of the household and marital status and regions of residence.

Figure A2: Difference-in-Differences (Duke Health Profiles)

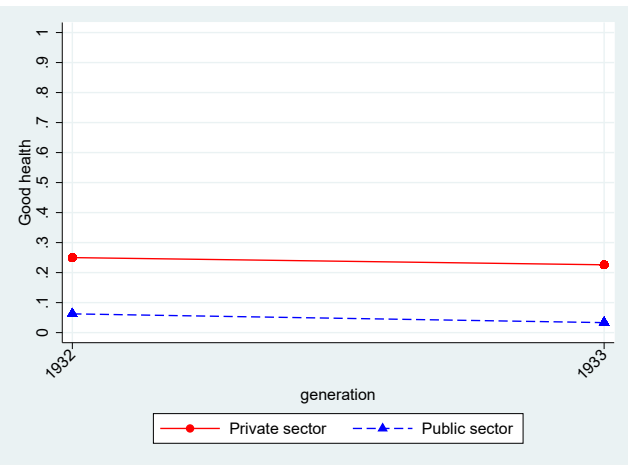

(a) Common trend

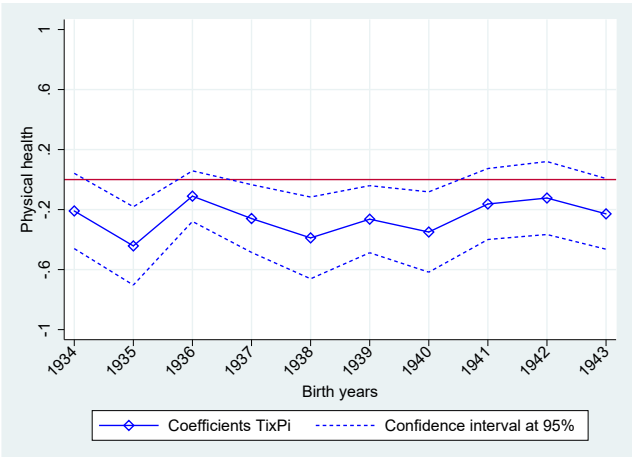

(b) Difference-in-Differences

Note: Figure A3a presents the common trend between generations 1932 and 1933, not affected by the reform (without control). In Figure A3b, Equation 4 is repeated for each cohort taken generation 1933 as control group. All regressions include treated $\left(T_{i}\right)$ and private sector $\left(P_{i}\right)$. For the first coefficient $T_{i}=1$ if the individual is born in 1934,0 if the individual is born in 1933. Controls are income, gender, numbers of children, education, size of the household and marital status and regions of residence.

Figure A3: Reform impact on the probability to report being in good health (less-educated individuals) 
Table A1: Number of observations by birth cohort for the baseline sample

\begin{tabular}{|c|c|c|}
\hline generation & Freq. & Percent \\
\hline 1928 & 23 & 0.5 \\
\hline 1929 & 164 & 3.6 \\
\hline 1930 & 283 & 6.1 \\
\hline 1931 & 264 & 5.7 \\
\hline 1932 & 267 & 5.8 \\
\hline 1933 & 287 & 6.2 \\
\hline 1934 & 290 & 6.3 \\
\hline 1935 & 313 & 6.8 \\
\hline 1936 & 318 & 6.9 \\
\hline 1937 & 322 & 7.0 \\
\hline 1938 & 362 & 7.8 \\
\hline 1939 & 355 & 7.7 \\
\hline 1940 & 321 & 7.0 \\
\hline 1941 & 323 & 7.0 \\
\hline 1942 & 330 & 7.1 \\
\hline 1943 & 397 & 8.6 \\
\hline Total & 4,619 & 100 \\
\hline
\end{tabular}

Table A2: PCS repartition in the public sector

\begin{tabular}{lcccc}
\hline Composition - public sector & Untreated & Treated & t-test & Observations \\
& $1928-1933$ & $1934-1943$ & $\mathrm{t}$ & $\mathrm{N}$ \\
\cline { 2 - 3 } Executives & $26.42 \%$ & $26.72 \%$ & -0.6296 & 1,258 \\
Intermediary professions & $35.56 \%$ & $38.79 \%$ & -0.5337 & 1,258 \\
Employees & $38.02 \%$ & $34.50 \%$ & 1.1223 & 1,258 \\
\hline
\end{tabular}


Table A3: Difference-in-Differences - Baseline analysis

\begin{tabular}{|c|c|c|c|c|c|c|c|c|}
\hline \multirow{3}{*}{$\mathrm{T} \times \mathrm{P}$} & \multicolumn{2}{|c|}{ Perceived health } & \multicolumn{2}{|c|}{ Physical health } & \multicolumn{2}{|c|}{ Mental health } & \multicolumn{2}{|c|}{ Social life } \\
\hline & $-6.987^{* *}$ & $-7.243^{*}$ & -2.666 & -3.543 & 0.0158 & -0.755 & 2.290 & 2.322 \\
\hline & $(3.539)$ & $(4.201)$ & $(2.128)$ & $(2.408)$ & $(2.045)$ & $(2.334)$ & $(1.879)$ & $(2.138)$ \\
\hline \multirow[t]{2}{*}{$\mathrm{T}$} & $9.810^{* * *}$ & 7.550 & $6.943^{* * *}$ & 1.797 & 0.993 & 2.391 & -0.674 & -1.554 \\
\hline & $(3.080)$ & $(4.977)$ & $(1.779)$ & $(2.960)$ & $(1.801)$ & $(2.819)$ & $(1.650)$ & $(2.492)$ \\
\hline \multirow[t]{2}{*}{$\mathrm{P}$} & $5.144^{*}$ & $8.665^{* *}$ & 1.471 & 3.339 & -0.113 & 0.129 & $-3.987^{* *}$ & -2.039 \\
\hline & $(3.075)$ & $(3.797)$ & $(1.822)$ & $(2.136)$ & $(1.764)$ & $(2.096)$ & $(1.628)$ & $(1.914)$ \\
\hline \multirow[t]{2}{*}{ age } & & 0.836 & & 5.529 & & 0.847 & & 2.704 \\
\hline & & $(8.060)$ & & $(5.276)$ & & $(4.563)$ & & $(4.127)$ \\
\hline \multirow[t]{2}{*}{$\operatorname{age}^{2}$} & & -0.008 & & -0.046 & & -0.0049 & & -0.011 \\
\hline & & $(0.061)$ & & $(0.040)$ & & $(0.035)$ & & $(0.031)$ \\
\hline \multirow[t]{2}{*}{ Men } & & 1.039 & & $9.378^{* * *}$ & & $5.536^{* * *}$ & & $-2.612^{* * *}$ \\
\hline & & $(1.624)$ & & $(1.061)$ & & $(0.930)$ & & $(0.862)$ \\
\hline \multirow[t]{2}{*}{ Household size } & & -0.514 & & -0.442 & & -1.395 & & $-1.475^{*}$ \\
\hline & & $(1.530)$ & & $(1.033)$ & & $(0.992)$ & & $(0.825)$ \\
\hline \multirow[t]{2}{*}{ Children (yes/no) } & & 2.651 & & 0.865 & & -0.738 & & 1.449 \\
\hline & & $(2.655)$ & & $(1.505)$ & & $(1.362)$ & & $(1.337)$ \\
\hline \multirow[t]{2}{*}{ Married } & & -2.292 & & 1.535 & & $4.673^{* * *}$ & & $3.691^{* * *}$ \\
\hline & & $(2.176)$ & & $(1.371)$ & & $(1.308)$ & & $(1.161)$ \\
\hline Observations & 2,986 & 2,280 & 2,965 & 2,267 & 2,960 & 2,266 & 2,931 & 2,248 \\
\hline
\end{tabular}

Note: robust standard errors in parentheses. ${ }^{* * *} \mathrm{P}$-value $<0.01,{ }^{* *} \mathrm{p}$-value $<0.05,{ }^{*}$ p-value $<0.1$. Additional controls are income, education and regions of residence. 
Table A4: Difference-in-Differences analysis

\begin{tabular}{lcccccc}
\hline \hline People born between 1929 and 1938 & & & & & & \\
& Without control & se & N & With controls & se & N \\
Panel A - All sample & & & & & & \\
Perceived health & $-10.201^{* *}$ & $(3.987)$ & 1888 & $-8.225^{*}$ & $(4.610)$ & 1411 \\
Physical health & -3.705 & $(2.410)$ & 1872 & -3.870 & $(2.733)$ & 1400 \\
Mental health & -0.169 & $(2.308)$ & 1868 & -0.637 & $(2.632)$ & 1401 \\
Social life & 2.228 & $(2.105)$ & 1847 & 2.912 & $(2.421)$ & 1387 \\
Panel B - Low-educated & & & & & & \\
Perceived health & $-16.867^{* * *}$ & $(5.582)$ & 1330 & $-15.489^{* *}$ & $(6.319)$ & 1033 \\
Physical health & $-7.238^{* *}$ & $(3.555)$ & 1316 & $-7.391^{*}$ & $(3.890)$ & 1023 \\
Mental health & -2.749 & $(3.779)$ & 1316 & -4.510 & $(4.019)$ & 1026 \\
Social life & -0.966 & $(2.921)$ & 1299 & -0.746 & $(3.318)$ & 1015 \\
Panel C - High-educated & & & & & & \\
Perceived health & -6.847 & $(6.369)$ & 558 & -3.986 & $(8.112)$ & 378 \\
Physical health & -1.801 & $(3.847)$ & 556 & 2.740 & $(4.625)$ & 377 \\
Mental health & -1.228 & $(3.231)$ & 552 & -1.349 & $(3.986)$ & 375 \\
Social life & 5.032 & $(3.423)$ & 548 & 4.546 & $(4.265)$ & 372 \\
\hline \hline
\end{tabular}

Note: robust standard errors in parentheses. ${ }^{* * *} \mathrm{P}$-value $<0.01,{ }^{* *}$ p-value $<0.05,{ }^{*}$ p-value $<0.1$. All regressions include treated $\left(T_{i}\right)$ and private sector $\left(P_{i}\right)$. Controls are age, age ${ }^{2}$, income, gender, children or not, education, size of the household and marital status and regions of residence.

Table A5: Difference-in-Difference analysis by cohort bracket without clusted standard errors

\begin{tabular}{lcccccc}
\hline \hline & Without control & s.e. & N & With controls & s.e. & N \\
People born between 1929 and 1938 & & & & & & \\
Perceived health & $-10.201^{* *}$ & $(3.987)$ & 1888 & $-8.225^{*}$ & $(4.610)$ & 1411 \\
Physical health & -3.705 & $(2.410)$ & 1872 & -3.870 & $(2.733)$ & 1400 \\
Mental health & -0.169 & $(2.308)$ & 1868 & -0.637 & $(2.632)$ & 1401 \\
Social life & 2.228 & $(2.105)$ & 1847 & 2.912 & $(2.421)$ & 1387 \\
People born between 1930 and 1937 & & & & & & \\
Perceived health & $-8.855^{* *}$ & $(4.496)$ & 1528 & $-8.397^{*}$ & $(5.082)$ & 1145 \\
Physical health & $-4.429^{*}$ & $(2.637)$ & 1512 & $-6.285^{* *}$ & $(2.956)$ & 1133 \\
Mental health & -1.967 & $(2.474)$ & 1511 & -3.534 & $(2.795)$ & 1136 \\
Social life & 3.039 & $(2.364)$ & 1499 & 3.593 & $(2.675)$ & 1127 \\
People born between 1931 and 1936 & & & & & & \\
\cline { 2 - 7 } Perceived health & -7.886 & $(5.274)$ & 1127 & -8.021 & $(5.818)$ & 853 \\
Physical health & $-6.015^{*}$ & $(3.084)$ & 1114 & $-6.363^{*}$ & $(3.443)$ & 844 \\
Mental health & 0.966 & $(2.914)$ & 1111 & -0.338 & $(3.239)$ & 843 \\
Social life & $5.178^{*}$ & $(2.756)$ & 1104 & 3.752 & $(3.179)$ & 837 \\
\hline \hline
\end{tabular}

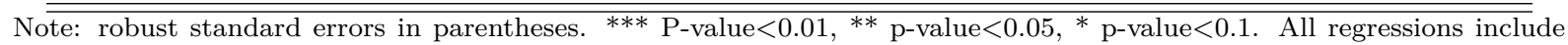
treated $\left(T_{i}\right)$ and private sector $\left(P_{i}\right)$. Controls are age, age ${ }^{2}$, income, gender, children or not, education, size of the household and marital status and regions of residence. 
Table A6: Difference-in-Differences analysis by cohort bracket with clustered standard errors

\begin{tabular}{|c|c|c|c|c|c|}
\hline & s.e. & $\mathrm{N}$ & With controls & s.e. & $\mathrm{N}$ \\
\hline \multicolumn{6}{|c|}{ People born between 1928 and 1943} \\
\hline Perceived health & $(2.208)$ & 2986 & $-7.243^{* * *}$ & $(2.402)$ & 2280 \\
\hline Physical health & $(2.289)$ & 2965 & -3.543 & $(3.219)$ & 2267 \\
\hline Mental health & $(2.746)$ & 2960 & -0.755 & $(2.882)$ & 2266 \\
\hline Social life & $(1.469)$ & 2931 & 2.322 & $(1.943)$ & 2248 \\
\hline \multicolumn{6}{|c|}{ People born between 1929 and 1938} \\
\hline Perceived health & $(2.749)$ & 1888 & $-8.225^{* * *}$ & $(2.618)$ & 1411 \\
\hline Physical health & $(2.320)$ & 1872 & -3.870 & $(3.297)$ & 1400 \\
\hline Mental health & $(3.244)$ & 1868 & -0.637 & $(3.931)$ & 1401 \\
\hline Social life & $(1.574)$ & 1847 & $2.912^{*}$ & $(1.769)$ & 1387 \\
\hline \multicolumn{6}{|c|}{ People born between 1930 and 1937} \\
\hline Perceived health & $(3.264)$ & 1528 & $-8.397^{* * *}$ & $(3.245)$ & 1145 \\
\hline Physical health & $(2.638)$ & 1512 & $-6.285^{* *}$ & $(2.959)$ & 1133 \\
\hline Mental health & $(3.154)$ & 1511 & -3.534 & $(3.423)$ & 1136 \\
\hline Social life & $(1.759)$ & 1499 & 3.593 & $(2.194)$ & 1127 \\
\hline \multicolumn{6}{|c|}{ People born between 1931 and 1936} \\
\hline Perceived health & $(4.417)$ & 1127 & $-8.021^{* *}$ & $(3.520)$ & 853 \\
\hline Physical health & $(3.266)$ & 1114 & $-6.363^{* *}$ & $(3.134)$ & 844 \\
\hline Mental health & $(3.258)$ & 1111 & -0.338 & $(3.604)$ & 843 \\
\hline Social life & (1.415) & 1104 & 3.752 & $(2.871)$ & 837 \\
\hline
\end{tabular}

Note: robust standard errors in parentheses. ${ }^{* * *} \mathrm{P}$-value $<0.01,{ }^{* *}$ p-value $<0.05,{ }^{*}$ p-value $<0.1$. All regressions include treated $\left(T_{i}\right)$ and private sector $\left(P_{i}\right)$. Controls are age, age ${ }^{2}$, income, gender, children or not, education, size of the household and marital status and regions of residence. With clustered standard errors that take into account the potential correlation within the same treatment cohort cell. 